This is a pre-print of an article published in Lingua. The final authenticated version is available online at: https://www.sciencedirect.com/science/article/pii/S0024384121000656

Please cite the published paper as:

Durand López, E. M. (2021). Morphological processing and individual frequency effects in L1 and L2 Spanish. Lingua, 257, 103093. https://doi.org/10.1016/j.lingua.2021.103093

\title{
Morphological processing and individual frequency effects in L1 and L2 Spanish
}

Ezequiel M. Durand López

Rutgers University

\section{Address for correspondence}

Correspondence concerning this article should be addressed to Ezequiel M. Durand López, 15 Seminary Place-West, 5185, New Brunswick, NJ 08901. Email address:

$\underline{\text { durand.ezequiel@ } @ \text { rutgers.edu }}$ 


\begin{abstract}
Surface frequency and proficiency modulate visual morphological processing in second language (L2) learners, but less is known about auditory morphological processing. Moreover, working memory affects morphosyntactic processing, but it is unclear whether it also modulates word structure processing. In the present study, Spanish monolinguals and beginner and advanced L2 learners of Spanish completed an auditory lexical decision task in Spanish containing verbs varying in morphological complexity, an individual surface frequency task, and a working memory task. Beginner L2 learners needed more time to process infrequent morphologically complex words, but monolinguals and advanced L2 learners were unaffected by morphological complexity or surface frequency. Also, working memory did not modulate morphological processing. Taken together, the findings suggest a dual-route mechanism at initial stages of L2 acquisition and a whole-word route for Spanish monolinguals and advanced L2 learners. The findings also support the extension of dual-route models to L2 populations and suggest that the selection of a morphological processing route results from linguistic rather than cognitive reasons.

Keywords: morphological processing, individual frequency, L2 processing, decomposition, Spanish language
\end{abstract}




\section{Morphological processing and individual frequency effects in L1 and L2 Spanish}

Frequency is a major variable affecting how speakers process incoming information in their first (L1) and second language (L2). Frequency affects a myriad of language processing abilities, including comprehending and producing phonology, morphosyntax, syntax and spelling (Ellis, 2002). Word frequency also predicts, according to certain word recognition models, how speakers process morphologically complex words. These proposals differ on whether speakers process words as stem+affix (the affix-stripping model, Taft, 2004), whole items (the full listing hypothesis, Butterworth, 1983), or stem+affix or whole units depending on contextual factors (the augmented addressed morphology model, AAM, per Burani, Salmaso \& Caramazza, 1984, and the morphological race model as in Schreuder \& Baayen, 1995). In most of these models, word frequency (either base frequency, i.e., the cumulative frequency of all the words in which the root occurs, or surface frequency, i.e., the frequency of a word as a whole) is a major factor modulating processing outcomes. Even though the said accounts have been formulated based on L1 data, many studies with L2 learners testing these models have been conducted in the last decade. In the following section, I will explain each of the word recognition models focusing on frequency, and I will mention the experimental studies conducted on bilingual morphological processing. The present study will aim at testing the assumptions of all word recognition models whose predictions include frequency effects 
and that do not solely rely on visual features (e.g., orthography), namely the affix-stripping model, the full listing hypothesis, the AAM and the morphological race model.

\section{The role of frequency in word recognition models}

\section{The affix-stripping model}

The affix-stripping model (Taft \& Forster, 1975; Taft, 1979, 1994, 2004) argues that native speakers automatically break words into their correspondent morphemes for morphological parsing, and they access information based on the stem. This account predicts that the recognition of morphologically complex words depends on the number of morphemes and word frequency. Speakers need more time to process words (a) with more morphemes than those with fewer morphemes and (b) with low base and surface frequency (Taft \& Ardasinski, 2006). In this model, frequency effects emerge because the entries are ordered based on their frequency, with the highest frequency entries being first on the search. The affix-stripping model is based on evidence from L1 studies (e.g., Beyersmann et al., 2013; Coughlin \& Tremblay, 2015; Duñabeitia, Perea \& Carreiras, 2007; Lewis, Solomyak \& Marantz, 2011; Longtin \& Meunier, 2005; Rastle, Davis, Marslen-Wilson \& Tyler, 2000; Stockall \& Marantz, 2006; Taft, 2004) and L2 studies (e.g., Coughlin \& Tremblay, 2015; De Grauwe, Lemhöfer, Willems \& Schriefers, 2014; Foote, 2017; Lehtonen \& Laine, 2003; Liang \& Chen, 2014) using a variety of experimental paradigms, from unprimed and primed lexical decision tasks to neurocognitive techniques. For example, Foote (2017), one of the very few L2 studies with Spanish, explored whether intermediate and advanced anglophone learners of Spanish processed morphologically complex words in a native-like manner. Participants completed a masked priming task 
containing complex Spanish verbs and nouns. Results showed that both L2 learners and natives took significantly more time to process unrelated primes than morphologically related primes. Foote (2017) concluded that attaining native-like processing of word structure (i.e., decomposition) is possible for adult learners of Spanish. In this study, however, critical words were matched for frequency. Thus, the effects of frequency on L1 and L2 processing of Spanish verb forms remain unanswered.

\section{The full listing hypothesis}

The full listing hypothesis (Butterworth, 1983) argues that words are stored as wholes in the lexicon and that they are available for recognition with their morphology complete. The number of morphological constituents is not expected to modulate how native speakers process word structure, but surface frequency might be a factor determining the speed in which the word is recognized. In this model, base frequency is discarded as a possible variable modulating morphological processing due to morphemes not being independent units available for processing in the early stages of word recognition. Several studies have gathered evidence for this model of lexical processing with native speakers (e.g., Gürel, 1999; Gürel \& Uygun, 2013; Lehtonen, Hultén, Rodríguez-Fornells, Cunillera, Tuomainen \& Laine, 2012; Portin \& Laine, 2001; Uygun \& Gürel, 2016). In addition, some theories of L2 acquisition and processing predict that late L2 learners do not make use of morphological information while processing the L2. Therefore, they might instead be using a whole word route (Clahsen \& Felser, 2006, 2018; Clahsen, Felser, Neubauer, Sato and Silva, 2010; Clahsen \& Neubauer, 2010). Other accounts support the whole word processing route indirectly. For example, the declarative/procedural model (Ullman, 2005) 
posits that L2 learners use their declarative memory to process the L2, which is linked to whole word processing.

\section{Dual-route paradigms}

Dual-route paradigms are hybrid models arguing that native speakers process morphologically complex words either as whole-word units or as stem+affix, depending on particular factors such as frequency. This paradigm includes the AAM (Burani \& Laudanna, 1992; Burani, Salmaso \& Caramazza, 1984; Caramazza, Laudanna \& Romani, 1988) and the morphological race model (Baayen, Dijkstra \& Schreuder, 1997; Baayen, Wurm \& Aycock, 2007; Schreuder \& Baayen, 1995). The AAM posits that native speakers deploy a full-parsing route while processing novel words, and either a direct route or a fullparsing route for familiar words, depending on surface frequency. More specifically, the AAM has systematically interpreted longer latencies for words with low surface frequency as a sign of morphological decomposition, and shorter latencies for words with high surface frequency as evidence they are processed as wholes (Burani, Salmaso \& Caramazza, 1984). Research supporting the AAM is found in L1 studies on homographs (Laudanna, Badecker \& Caramazza, 1989, 1992), opposite-gender inflected homographs (Domínguez, de Vega \& Barber, 2004), morphologically manipulated nonwords (Caramazza, Laudanna \& Romani, 1988), inflected words (Lehtonen \& Laine, 2003), and derived words (Burani \& Caramaza, 1987; Vannest, Bertram, Järvikivi \& Niemi, 2002).

Experimental studies providing evidence for a dual route of bilingual morphological processing have emerged in recent years (e.g., Chen, Miao \& Fang, 2007; Estivalet \& Meunier, 2019; Gürel \& Uygun, 2013; Lehtonen, Niska, Wande, Niemi \& Laine, 2006;

Portin, Lehtonen \& Laine, 2007; Soveri, Lehtonen \& Laine, 2007). For example, Gürel and 
Uygun (2013) compared Turkish monolinguals to Turkish L2 learners' performance on an unprimed lexical decision task that included monomorphemic and multimorphemic Turkish words. While some experimental items had a highly frequent suffix (e.g., plural), other words had a low-frequency Turkish case (e.g., ablative). Monolinguals did not display longer response times (RTs) in multimorphemic words than in monomorphemic words, which suggests that they have whole word representations. On the other hand, low proficient learners decomposed the words, but advanced L2 learners of Turkish presented more native-like processing patterns. However, in this study surface frequency was not calculated per item; the researchers assumed that words with the ablative suffix would have lower surface frequency than words with locative suffix, which might not be the case for specific lexical items. Also, the stimuli were not controlled for syllable length, which might have affected the results considerably.

A second model within the dual-route paradigm is the morphological race model, which argues that the direct route is a spreading activation network that maps a whole-word access representation onto the lemma interface it is associated with. The parallel parsing operation, in turn, activates both morphemes and whole words, checks morphosyntactic compatibility features, and accesses the meaning of the complex word. Base frequency as well as semantic transparency determine the activation of either route. Specifically, lowbase-frequency, transparent words undergo parsing, while high-base-frequency and opaque words are likely to be processed as full forms. There is abundant experimental evidence in favor of the morphological race model from research with native speakers (e.g., Kuperman, Bertram \& Baayen, 2008; McCormick, Brysbaert \& Rastle, 2009; Meunier \& Longtin, 2007), but no L2 studies, to the best my knowledge. 


\section{Working memory and language processing}

$\mathrm{WM}$ is the cognitive system(s) responsible for the control, regulation, and active maintenance of information in the face of distracting information (e.g., Conway, Jarrold, Kane, Miyake \& Towse, 2007). This construct was originally proposed by Baddeley and Hitch (1974), who conceived the system as two separable sub-systems: a short-term, storage-based system (i.e., slave systems, including the visuospatial sketchpad and the phonological loop), and an executive, attentional system that allocated attention and controlled the information in the short-term stores. An episodic buffer was later introduced (Baddeley, 2000), which was conceived as an interface between the three systems and longterm memory.

The relationship between WM and L1 acquisition and processing is well established (see Gathercole \& Baddeley, 2014 for a comprehensive review). WM has also been associated with a myriad of L2 acquisition and processing aspects (see Wen, Mota \& McNeill, 2015 for a review). Importantly, WM has been linked to L2 morphosyntactic processing (e.g., Coughlin \& Tremblay, 2013; Dronjic, 2013; Havik, Roberts, Van Hout, Schreuder \& Haverkort, 2009; Sagarra, 2007; Sagarra \& Herschensohn, 2010; but see Rodríguez, 2008 for no WM correlations). While deficit, computational accounts posit that adult L2 learners cannot reach native like processing of an L2 (Clahsen \& Felser, 2006, 2018), accessibility, computational theories claim that adult learners' difficulty processing L2 morphosyntax is due principally to WM limitations, given the high demand of operating in L2 (McDonald, 2006). This association is highly relevant for the present study, as no prior studies, to the best of my knowledge, have explored whether the selection of a particular route (i.e., decomposition or whole word processing) is due to cognitive 
constraints or to linguistic reasons. It could be argued that upon processing words made up of several derivational or inflectional morphemes, a speaker would have to hold either pure morphological (i.e., inflectional morphemes) or semantic (i.e., stems and derivational affixes) information in memory while processing the remaining word structure, thus requiring them to make use of their WM. On the other hand, and at least in nonagglutinating languages like Spanish, morphological computation may not be considered to be as taxing as the processing of morphosyntax. For the latter process, the processor also needs to compute other linguistic information such as hierarchical operations (i.e., agreement, movement), thematic roles, word order, and lexical semantics. However, some individuals with particularly low WM may have difficulty parsing words in the L2, further motivating the need for more research regarding the relationship between WM and L2 learners' processing of L2 morphology. This is important as it would provide further information about how general-purpose cognitive abilities intervene in linguistic processes at the word level.

\section{The study}

Existing morphological processing models only make predictions about monolingual populations. In the last decades, however, an increasing number of studies have tried to extend these models to L2 learners. Nevertheless, many critical aspects about morphological processing in the L2 remain unclear.

First, most experimental studies include stimuli varying in corpus-based surface frequency. A word that is allegedly found to be more or less common in a given corpus does not necessarily reflect, however, how frequent that word is for a given person, as each person's vocabulary is different due to their profession, communicative needs, social 
interaction, or educational level. Corpus-based surface frequency may also underestimate words that are generally known to speakers of a certain language but that are not frequent in a given corpus. In addition, word frequency can vary tremendously among corpora depending on the type of corpus chosen (e.g., written, spoken, academic, fiction). Some of these reasons have recently led researchers in Second Language Acquisition to start employing self-reported frequency measures instead of corpora (e.g., Hur, 2021; Hur, López Otero \& Sánchez, 2020; López Otero, 2020). Therefore, studies examining lexical access theories are encouraged to also use individual frequency (i.e., the frequency of a word for a given speaker).

Second, little research on word structure processing has been conducted with the Spanish language, of import because it is still unclear whether morphological processing is universal (Beyersmann, Duñabeitia, Carreiras, Coltheart \& Castles, 2013). Therefore, if each language has a default morphological processing mechanism, it is appropriate to explore which one is characteristic of the Spanish language.

Third, it is unclear whether the selection of a particular route (i.e., decomposition or whole unit processing) is due to cognitive constraints. More specifically, the literature has not addressed potential effects of WM, a cognitive ability associated with morphosyntactic processing, on the processing of word structure in either the L1 or the L2. This information would allow future research to reformulate models arguing that L2 sentence processing heavily relies on WM (e.g., McDonald, 2006), and also extend it to L2 processing of morphology.

Fourth, some word recognition studies have interpreted longer latencies in low frequency words as a sign of decomposition (Burani, Salmaso \& Caramazza, 1984). 
However, it could be argued that highly frequent words are recognized faster only because they are more frequently activated in the lexicon (e.g., Aguasvivas, Carreiras, Brysbaert, Mandera, Keuleers \& Duñabeitia, 2020). One can compare frequency effects in RTs with a ream of papers. Whenever a piece of paper placed anywhere in the pile is needed, it can be retrieved and then placed on top of the pile. Depending on the need for that paper, it could easily go down in the pile as other sheets of papers are needed and placed on top. As some scholars have suggested, the word frequency effect, therefore, should not be mistaken as a sign of morphological decomposition (Lignos \& Gorman, 2012). In order to make the claim that the processor makes use of morphological manipulation strategies to efficiently overcome the word recognition process, differences in RTs between words with differing numbers of morphemes should be found. Finally, to establish whether frequency modulates the strategy the processor opts for, an experimental design that compares words with different numbers of morphemes with varying frequency as reported by the participants should be adopted.

To address the theoretical and methodological concerns explained above, the present study examines the role of L2 proficiency, individual frequency, morphological complexity and WM in the auditory processing of derived verbs in Spanish monolinguals and anglophone L2 learners of Spanish. It adds to the previous morphological processing studies in that (a) it focuses on an understudied population, namely Spanish monolinguals and L2 learners of Spanish, (b) it measures each participant's exposure to each experimental word, (c) it examines the relationship between WM and word structure processing, and (d) it examines spoken word recognition, a type of processing much less explored than its visual counterpart. The research questions are as follows: 
RQ 1: Do beginner and advanced English L2 learners of Spanish employ the same morphological processing strategies (i.e., parsing or a whole unit processing) as Spanish monolinguals while processing L2 words? Does the selection of the processing strategy change as a function of their proficiency in their L2?

I expect the monolinguals and advanced L2 learners to process highly frequent words as whole units and low frequent ones as fully decomposed, and the beginners to process all L2 words as stem+suffix, regardless of their frequency.

RQ 2: Does WM capacity affect how Spanish monolinguals and beginning and advanced English L2 learners of Spanish process morphologically complex words in the target language?

I predict that WM capacity will not be associated with lexical processing in any group. This hypothesis is based on the fact that processing a word's morphology is not as taxing as morphosyntactic processing, thus not relying heavily on WM.

The findings of the current study may be informative about fundamental factors in L1 and L2 morphological processing, such as the role of individual exposure to a given language and word, proficiency in the L2, WM, and the role of morphological complexity. More globally, conclusions drawn from the study might account for how bilinguals modify their cognitive processing strategies as they further advance on the acquisition of a L2.

\section{Method}

\section{Participants}

The sample pool consisted of 101 participants: 26 Spanish monolinguals, 39 beginner and 36 advanced English late L2 learners of Spanish. To be included in the study, participants could not have spent more than two months in a country whose societal 
language was one other than English (for L2 learners of Spanish) or Spanish (for Spanish monolinguals), and they had to have performed perfectly on a vocabulary test. Nine beginner and two advanced L2 learners failed to match all words with their correct translation, which might be an indication that they did not know the meaning of these words. Therefore, data for these participants were not included in statistical analyses. After these exclusions, the final sample included 90 participants. All participants were students in a major North American (L2 learners) or South American (Spanish monolinguals) university, majoring in an area other than linguistics. All were between 18 and 38 years old $(M=23.03, S D=5.99)$ and right-handed. Beginning L2 learners were enrolled in a $4^{\text {th }}$ semester Spanish class, while advanced L2 learners were students in a Spanish graduate program. The Spanish monolingual group was born and raised in Buenos Aires, Argentina, had studied English in middle school and high school but had not continued studying this language after school. Finally, all participants reported having normal hearing and normal or corrected-to-normal vision.

\section{Procedure}

The L2 learners performed six tasks in an hour-long session. The tasks were conducted in the following order: the language background questionnaire (10 minutes), the Spanish proficiency test (15 minutes), the auditory lexical decision task (15 minutes), the WM task (10 minutes), the translation recognition task (5 minutes), and the self-reported lexical frequency task (5 minutes). The Spanish monolinguals completed the same tasks, except for the Spanish proficiency test and the translation recognition task, and their experimental session lasted 40 minutes. Upon arriving at the laboratory room, participants were engaged in informal chatting with the researcher for a few minutes in Spanish, to 
foster their activation of this language as a warm-up for the upcoming tasks in Spanish (see Grosjean, 1998 for an explanation about bilingual modes and the importance of activation of the target language for methodological purposes). All tasks, with the sole exception of the WM task for L2 learners, were explained and conducted in Spanish.

\section{Materials}

\section{Language background questionnaire}

The language background questionnaire consisted of three sections. The first one contained six autobiographical questions (e.g., gender, age, date of birth, etc.). The second section contained nine questions regarding the linguistic and cultural history of the participant. The third section focused on each of the languages the participant spoke, and required factual information (e.g., time spent in a Spanish speaking country), and selfperceived scores about the participant's dominance of different linguistic skills in the L2.

The mean age of acquisition of the late L2 learner group was 13.7 years $(S D=1.2)$. Moreover, all the L2 speakers were born and raised in the United States and had not been exposed to the Spanish language at home. Based on the LEAP-Q, monolinguals had been born and raised in Buenos Aires, Argentina, and had not studied any second language besides that of the requirement in middle school and high school. Self-perceived ratings for proficiency in a second language showed a low functional proficiency level $(M=2.5$ out of $10, S D=2.2)$.

\section{Spanish proficiency test}

The L2 speaker groups completed an abridged version of the grammar section of the Diploma de Español como Lengua Extranjera (DELE) to measure their proficiency in the target language. In this multiple-choice grammar test, L2 participants read isolated 
sentences and a short text in Spanish and were instructed to fill in the blanks with one of four options. Correct answers received 1 point, and participants could obtain a maximum of 50 points. Beginning L2 learners had an average of 20.5 points $(S D=1.4)$, while advanced L2 learners scored an average of 41.1 points $(S D=1.2)$. Previous studies using this task have used cut-off points of 30 and 40 points for beginners and advanced L2 learners, respectively (e.g., Slabakova, Kempchinsky \& Rothman, 2012). Finally, a t-test for independent samples indicated that the advanced L2 learners' DELE mean scores were significantly higher than those of the beginner group, $t(1271)=-54.31, p<.001$.

\section{Auditory lexical decision task}

All groups completed an auditory lexical decision task containing 144 items, made up of 48 experimental words and 48 pseudowords (66\%) and 48 distractors (33\%).

Distractors pertained to another experiment whose results are not reported herein; half of them were real Spanish words, and the other half were pseudowords. Participants sat in front of a computer and wore noise-cancelling headsets; in Spanish, they were instructed to decide as fast and as accurately as possible whether the word they heard was a real word in Spanish or not. Participants pressed a yes button for real Spanish words and a no button for non-Spanish words. Handedness was controlled for by having half of the subjects press the left button for yes, and the other half, for no. RTs and accuracy for every word were recorded. Before listening to the 144 items, participants practiced with 6 items.

Experimental and filler items were recorded through a computerized voice. In order to generate a recording of each word, the Watson Text to Speech software (Santiago, Singh \& Sri, 2017) was used, providing each word recording with the acoustic characteristics of an adult male. 
Half of the experimental words were real Spanish words and half were pseudowords following legal Spanish phonotactics. Pseudowords were based on each of the experimental Spanish words, they shared the first phoneme /a/ but they had two phonemes replaced (e.g., ahogar /a.o' ֻ̦ar/ 'to drown' > /a.u'kar/; aceitar /a.sei 'tar/ 'to oil' > /a.xer'tar/). A t-test for independent samples showed no statistically significant differences on phonotactic probability between experimental words and pseudowords $t(94)=-3.18, p=.35$.

Stimuli for the auditory lexical decision task varied in their number of morphemes. Half of the experimental real words had two morphemes (e.g., abrig-ar, arroj-ar) and the other half had three morphemes (e.g., a-rruin-ar, a-larg-ar) (see Appendix A for the complete list of experimental real words). All of the experimental words had a base (which would be an autonomous base after the decomposition of the verb) and an inflectional morpheme (i.e., the infinitival suffix for the first Spanish verb conjugation -ar). In addition, words with three morphemes had one more morpheme, a derivational prefix (i.e., $a$-) attached to the base. In Spanish, the derivational prefix $a$ - can be attached to nouns, adjectives or adverbs, changing the syntactic category of the base, transforming the original word into a verb. For example, the Spanish adjective larg-o 'long' can transform into the verb $a$-larg-ar 'to lengthen' by adding two morphemes: the derivational prefix $a$ - and the inflectional suffix -ar. This morphological process, known as parasynthesis (i.e., the simultaneous addition of a prefix and a suffix) is widespread in the Spanish language (Serrano-Dolader, 2017). An ideal comparison would include words made up of several morphemes with monomorphemic words, but in Spanish, the addition of morphemes to a lexical item most of the times entails the addition of more syllables (e.g., pez, peces, pececitos; 'fish-singular', 'fish-plural', 'little fish-plural'). Words with more syllables 
correlate with longer RTs, which muddles the results (Chetail, 2014). Therefore, only experimental items differing in one morpheme were included, and syllable length (i.e., three) was kept constant across conditions. Moreover, the computerized recording length in milliseconds for experimental words with two morphemes $(M=628.66, S D=66.85)$ was almost identical to that of words with three morphemes $(M=627.20, S D=72.72)$, and the recording length for real words $(M=627.94, S D=69.02)$ was similar to that of pseudowords $(M=609.82, S D=57.04)$. Two t-tests for independent samples indicated that there was no significant difference across conditions, $t(46)=.07, p=.818$ or between experimental words and pseudowords, $t(94)=1.40, \mathrm{p}=.175$.

Experimental words were matched for a number of variables affecting RTs, including syllable number (three syllables), lexical category (infinitival forms), affix productivity (all words shared the same derivational prefix $a$ - and the same inflectional suffix -ar), phonotactic probability, and neighborhood density. An explanation of every variable that has been matched for the experimental items will be provided as follows.

First, neighborhood density is the number of phonological neighbors (words differing by a single phoneme) a word has. In lexical decision tasks in Spanish, RTs tend to be shorter as density increases (see Vitevitch \& Luce, 2016 for a comprehensive analysis of neighborhood density effects). The Spanish neighborhood density calculator in the NIM database (Guasch et al., 2013) was used to calculate the neighborhood density of every word. An independent sample t-test showed no statistically significant differences of neighborhood density between experimental derived verbs and their solely inflectional counterparts, $t(45.85)=.10, p=.925$. 
Second, phonotactic probability is the frequency with which sequences of phonemes and their segments occur within the linguistic items of a given language (Vitevitch \& Luce, 2005). Phonological sequences that occur more often in a given position within a word in a given language have a high phonotactic probability (e.g., /b/ at the beginning of a Spanish word), while others that are less frequent (e.g., /x/ in reloj in Spanish) are considered to have a low phonotactic probability. Lexical access studies using either auditory or visual stimuli should also control for this variable, as it has been shown that highly frequent phonotactic combinations produce shorter RTs, while infrequent patterns in a word slows down word recognition (Auer \& Luce, 2005). The Phonotactic Probability Calculator of Spanish (Vitevitch \& Luce, 2004) was used to measure the phonotactic probability of every experimental word and pseudoword. The sum of all the phoneme probabilities and all the biphone probabilities generated the general phonotactic probability score. Two t-tests for independent samples revealed no significant differences in phonotactic probability among words across conditions, $t(41.89)=-.59, p=.557$, or between words and pseudowords, $t(94)=-3.18, p=.633$.

Third, affix productivity refers to the amount of words a certain affix appears in a given language (e.g., the infinitival suffix -ir is less productive than -er in Spanish). Several studies have suggested that morphologically complex words with unproductive affixes are processed differently than those with productive ones during online recognition (Lázaro, 2012). All experimental words and pseudowords were verbs ending in the same suffix (ar), and all items, whether or not they were complex items, started with the same prefix (for verbs with inflectional and derivational morphemes) or phoneme (for verbs with an inflectional suffix only), $a-$. 
Finally, surface frequency of the experimental words was measured using the LEXESP corpus (Sebastián-Gallés, Martí, Carreiras \& Cuetos, 2000). A t-test for independent samples revealed that the corpus-based surface frequency for words with two morphemes $(M=2.61, S D=1.70)$ was similar to that of words with three morphemes $(M=$ 2.64, $S D=2.15), t(43.71)=-.06, p=.955$.

\section{Math span task}

All groups completed a Math span task, which is a non-language related psychometric test designed to measure WM (Shahnazari-Dorcheh \& Roshan, 2012). WM is normally measured by tasks that can be language-related (e.g., reading or listening span task) or non-language-related (e.g., operation span task). Non-language related tasks are usually preferred, as language-specific tasks differ from one language into the other. In addition, a reliable score for WM capacity may not be obtained by using languagedependent measures of memory tasks as memory spans are confounded with L2 proficiency (e.g., Juffs \& Harrington, 2011). This is the reason why participants performed the WM task in their L1 (English for the L2 speaker group and Spanish for the monolingual group), along with the fact that WM seems to be language independent (e.g., Osaka \& Osaka, 1992; Xue, Dong, Jin \& Chen, 2004). However, the performance of these two groups is not necessarily comparable. This task could be thought to be more challenging for Spanish speakers, as many numbers in this language are polysyllabic (e.g., ocho, nueve, doce), while English polysyllabic numbers used in the task are limited to a couple examples. It is possible that Spanish monolinguals had less time for saying the result of the operations (due to numbers in Spanish being phonetically longer) and that it was more cognitively taxing for them, as they had to merge the syllables together. 
For this task, a series of basic addition and subtraction calculations (e.g., $7+6=$ ?) were presented on a computer screen. Participants were to say the result of these calculations aloud (processing) and they were instructed to remember the second digit of each calculation, which involves storage (in the case of $7+6,6$ is the target number to be remembered). Stimuli were presented in 15 sets of increasing number of calculations, starting with only two operations up to six calculations. The time between operations was 2.5 seconds.

Participants were given 1 point per calculation (if they said the right number before the next calculation showed on the screen) and 1 point per second digit recalled in the correct order. If the digit was recalled correctly but in a different order, no points were given. Total possible points for processing added up to 60 points, and 60 possible points for storage, which brings a total of 120 points, the WM span. Two one-way ANOVAs showed that both overall WM capacity, $F(2,89)=4.33, p=.016$, and its storage component, $F(2$, $89)=7.50, p=.001$, were uneven across groups. With regard to overall WM, a Tukey posthoc test showed that advanced L2 learners $(M=94.97, S D=11.77, p=.012)$, but not beginners $(M=92.13, S D=11.47, p=.155)$ had significantly higher WM spans than Spanish monolinguals $(M=86.73, S D=8.39)$. Regarding the storage component of WM, a Tukey post-hoc test revealed a similar scenario, as monolinguals $(M=25.85, S D=6.77)$ had a significantly lower WM storage spans than their beginning $(M=33.20, S D=11.47, p$ $=.024)$ and advanced $(M=36.03, S D=11.26, p=.001)$ L2 learner peers. These results are consistent with previous findings in the literature (e.g., Cockcroft, Wigdorowitz \& Liversage, 2019; Durand López, In press), which is frequently interpreted as a sign of a bilingual advantage in memory capacity. 


\section{Translation recognition task}

In order to ensure that L2 speakers were familiar with the meaning of the real words used in the auditory lexical decision task, they performed a translation recognition task containing all experimental items. In this paper-and-pencil task, participants matched the Spanish words that were located in a column on the left with their translations in English that were randomized in a column on the right. The maximum possible score was 48 (1 point per Spanish word-English translation). To be included in the study, participants could not make any errors in this task, a decision I made to ensure that longer latencies did not result from their searching for a lexical entry not stored in their lexicon.

Although offline picture-naming tasks are the standard way to assess semantic knowledge in bilinguals (Gollan, Montoya, Fennema-Notestine \& Morris, 2005), this task could not be performed in the study for a technical impediment: it was difficult to draw a representation of the experimental verbs. Thus, it would have been arduous for participants

to identify them through a drawing. However, the translation recognition task is informative regarding their semantic knowledge of the experimental words, as perfect scoring in the task is a requirement for the inclusion in the data analyses of the study, which keeps bychance matchings to a bare minimum.

\section{Self-reported surface frequency task}

Finally, participants completed a self-reported lexical frequency task through a Likert scale. The task was performed with the aim of measuring the best predictor of frequency effects in morphological processing (i.e., individual surface frequency). In this paper-and-pencil task, participants were to rate from 1 to 4 how frequently they heard and said all the experimental items they had heard. The Likert scale was designed with an even 
number to force participants to decide between the infrequent spectrum (1-2) and the frequent one (3-4). As expected, the correlations between corpus-based frequency and selfreported surface frequency (i.e., individual frequency) ranged from weak to very weak for L2 learners (for beginners: $r(862)=.08, p=.01$; for advanced learners: $r(503)=.27, p<$ $.05)$ and medium for natives: $r(382)=.39, p<.05)$. These data further support the notion that corpus-based frequency might not be suitable for gauging individual frequency, especially for L2 learners, as other scholars have proposed (e.g., Hur, 2021; Hur et al., 2020; López Otero, 2020).

\section{Results}

The auditory lexical decision task generated two scores: accuracy and RTs. Only RTs associated with experimental items and correct responses were included in the statistical analyses. This procedure is standard in studies using lexical decision tasks, as it is performed in order to ensure that the participant was paying attention during the processing of each specific word (e.g., Foote, 2017; Lázaro, 2012). RTs were normalized using the orderNorm function in the bestNormalize package in R (R Core Team, 2020), which inverse-transformed all RTs (i.e., -1000/RT). Descriptive statistics for real words are found in Table 1.

\section{Table 1}

Means and SD in ms for RTs and accuracy across groups, individual surface frequency and number of morphemes.

\begin{tabular}{|c|c|c|c|c|c|c|}
\multicolumn{2}{|c}{ ISF } & $\begin{array}{c}\text { Number of } \\
\text { morphemes }\end{array}$ & $\begin{array}{c}\text { RTs } \\
(\boldsymbol{M})\end{array}$ & $\begin{array}{c}\text { RTs } \\
(\text { SD) }\end{array}$ & $\begin{array}{c}\text { Accuracy } \\
(\boldsymbol{M})\end{array}$ & $\begin{array}{c}\text { Accuracy } \\
\text { (SD) }\end{array}$ \\
\hline Broup & & 2 & 927.64 & 433.29 & 0.79 & 0.40 \\
\hline Beginner & High & 2 & 826.65 & 255.79 & 0.70 & 0.46 \\
\hline
\end{tabular}




\begin{tabular}{|c|c|c|c|c|c|c|}
\hline Beginner & Low & 2 & 932.62 & 384.30 & 0.67 & 0.39 \\
\hline Beginner & Low & 3 & 1050.86 & 391.52 & 0.62 & 0.40 \\
\hline Advanced & High & 2 & 646.27 & 179.21 & 0.97 & 0.14 \\
\hline Advanced & High & 3 & 646.54 & 170.24 & 0.96 & 0.18 \\
\hline Advanced & Low & 2 & 673.40 & 203.00 & 0.75 & 0.42 \\
\hline Advanced & Low & 3 & 690.91 & 201.16 & 0.67 & 0.46 \\
\hline Native & High & 2 & 599.43 & 270.27 & 1.00 & 0.00 \\
\hline Native & High & 3 & 555.52 & 201.32 & 0.98 & 0.11 \\
\hline Native & Low & 2 & 611.42 & 245.76 & 0.95 & 0.21 \\
\hline Native & Low & 3 & 587.97 & 185.76 & 0.95 & 0.20 \\
\hline
\end{tabular}

A generalized linear mixed model (GLMM), run through the glmer function in the lme4 package (Bates \& Maechler, 2009), with group (beginners, advanced, monolinguals), individual surface frequency (low and high) and number of morphemes (two and three) as fixed factors and all their possible interactions, including subject and item as random factors on word accuracy revealed a main effect of group, $\chi^{2}(4)=70.92, p<.001$, and of individual surface frequency, $\chi^{2}(2)=9.90, p=.007$. Pairwise comparisons were adjusted for multiple comparisons using the Tukey posthoc test. With regard to the main effect of group, both native speakers $(p<.001, d=3.11)$ and advanced L2 learners $(p<.001, d=$ 2.22) were significantly more accurate than beginners. Moreover, participants did not respond to words that were highly frequent for them significantly more accurately than to those with which they were acquainted with but were low frequent for them overall $(p=$ 
$.99, d=3.86)$. However, there was a significant interaction of group and individual surface frequency, $\chi^{2}(2)=11.37, p=.003$. Pairwise comparisons revealed that both advanced L2 learners $(p<.001, d=2.29)$ on the one hand, and Spanish native speakers $(p=.004, d=$ 9.13) on the other hand, were significantly more accurate when responding to words with high than with low frequency. Beginners, however, were not significantly more accurate with highly frequent words than with those that were not frequent for them $(p=.99, d=$ $.17)$. This result is shown in figure 1 .

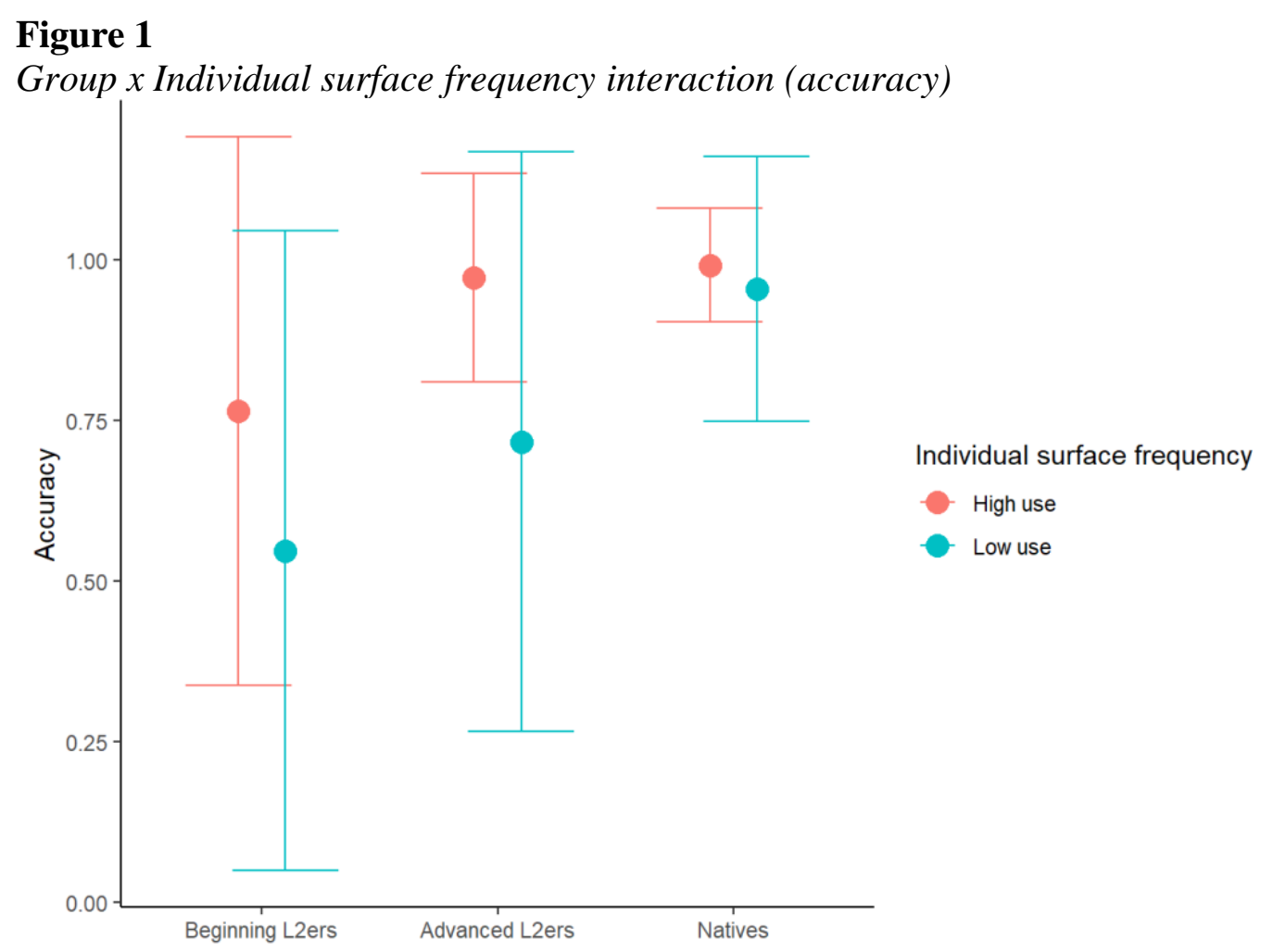

Another GLMM with group, individual surface frequency, and number of morphemes as fixed factors and subject and item as random factors was carried out on the RT data in order to explore whether participants decomposed the words presented to them. Results revealed a significant main effect of group, $\chi^{2}(2)=89.76, p<.001$ and individual 
frequency, $\chi^{2}(1)=5.67, p=.017$ on RTs. Regarding the main effect of group, Tukeyadjusted pairwise comparisons showed that native speakers were significantly faster than beginners $(p<.001, d=1.43)$, and that advanced L2 learners were significantly faster than their beginner peers $(p<.001, d=1.11)$. Also, advanced L2 learners were not significantly slower than native speakers $(p=.26, d=.32)$. With regard to the main effect of individual frequency, a post-hoc test revealed that words used less frequently were responded to significantly more slowly than words that were highly frequent for the participants $(p<$ $.001, d=.29$ ). In addition, the model detected three significant interactions: (a) group and individual surface frequency, $\chi^{2}(2)=8.83, p=.012$, (b) group and number of morphemes, $\chi^{2}(2)=5.99, p=.049$, and (c) group, number of morphemes and individual surface frequency, $\chi^{2}(2)=6.17, p=.045$. For the first interaction, Tukey-adjusted pairwise comparisons revealed that beginning L2 learners $(p<.001, d=.72)$, but not their advanced peers $(p=.66, d=.17)$ or Spanish monolinguals $(p=1, d=.003)$ took significantly more time to process low frequent words than highly frequent ones. For the significant group $\mathrm{x}$ number of morphemes interaction, none of the groups took significantly more time to process derived verbs with varying number of morphemes (beginners: $p=.99, d=.03$; advanced: $p=1, d=.002$; natives: $p=.84, d=.14$ ). However, a post-hoc test for the triple group $\mathrm{x}$ number of morphemes $\mathrm{x}$ individual surface frequency interaction revealed that beginners processed words with three morphemes with low frequency significantly slower than words with two morphemes with low frequency $(p=.037, d=.47)$, and that beginners took a similar amount of time to process words with three morphemes with high frequency than words with two morphemes with high frequency $(p=.85, d=.55)$. On the other hand, advanced L2 learners $(p=.99, d=.044)$ and Spanish monolinguals $(p=.99, d=.085)$ took 
a similar amount of time to process words with two morphemes with low frequency than words with three morphemes with low frequency. Finally, the said two groups also took a similar amount of time to process words with three morphemes with high frequency than words with two morphemes with high frequency (advanced: $p=1, d=.040$; natives: $p=$ $.99, d=.21)$. See Figure 2 for the visual representation of these effects.

\section{Figure 2}

Group $x$ individual frequency $x$ number of morphemes interaction (RTs)

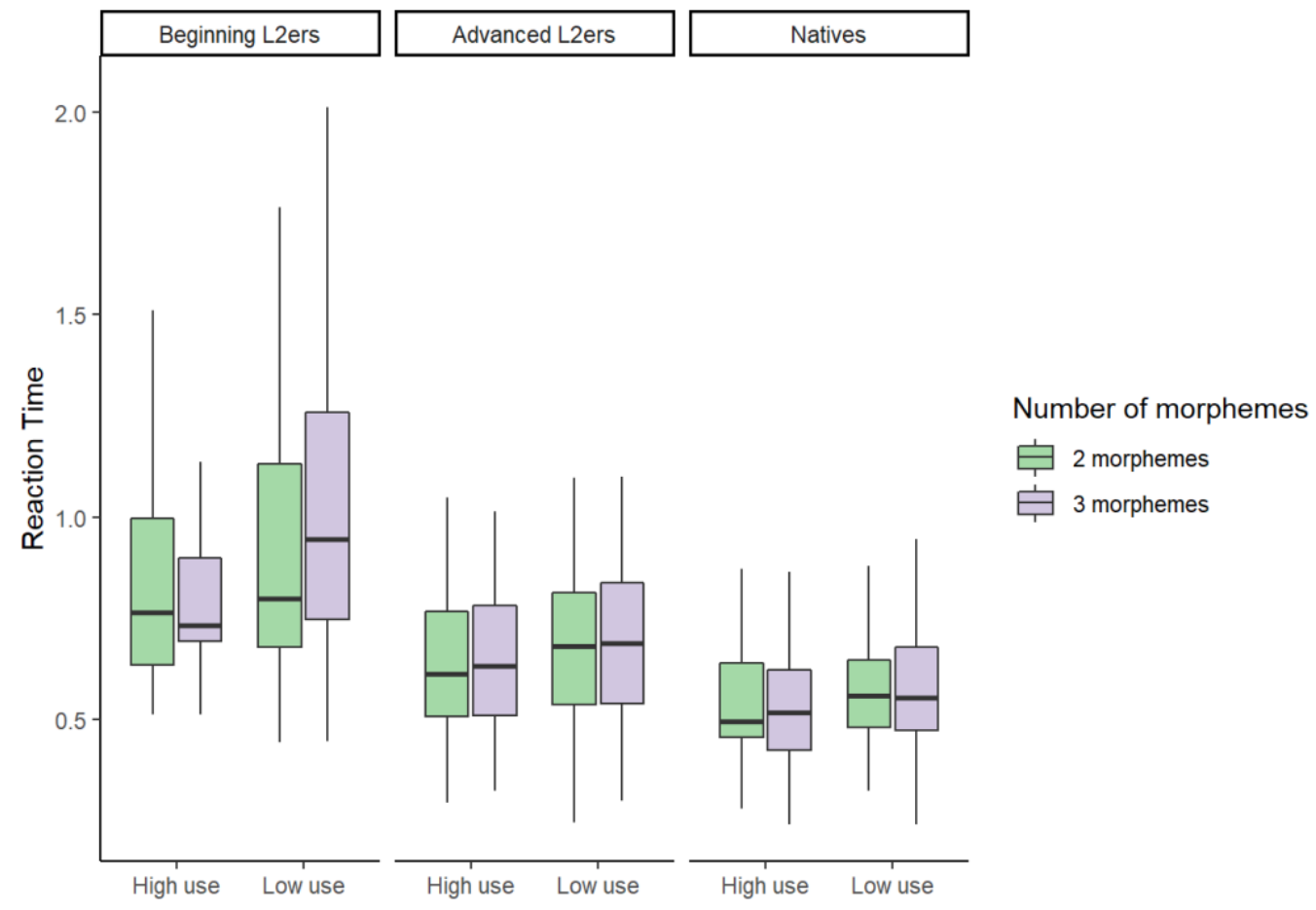

With the aim of exploring potential effects of WM capacity on the adoption of a specific morphological processing route, a third GLMM was run to predict RTs based on group, number of morphemes, individual surface frequency, and WM capacity as fixed factors and subject and item as random factors. Results showed a main effect of WM capacity, $\chi^{2}(1)=10.044, p=.001$ and group, $\chi^{2}(2)=69.19, p<.001$ on RTs, as well as an 
interaction of these two variables, $\chi^{2}(2)=10.588, p<.001$. A post-hoc test for the interaction showed a negative association between WM capacity and RTs for the beginner group, suggesting that the higher the beginning L2 learners' WM capacity, the faster they responded to stimuli $(p<.05)$. See Figure 3 for the visual representation of these effects.

On the other hand, the test failed to find a significant main effect of number of morphemes, $\chi^{2}(1)=0.85, p=.35$, or a significant group $\mathrm{x}$ WM capacity $\mathrm{x}$ number of morphemes interaction, $\chi^{2}(2)=1.88, p=.16$.

\section{Figure 3}

Association between WM capacity and RTs

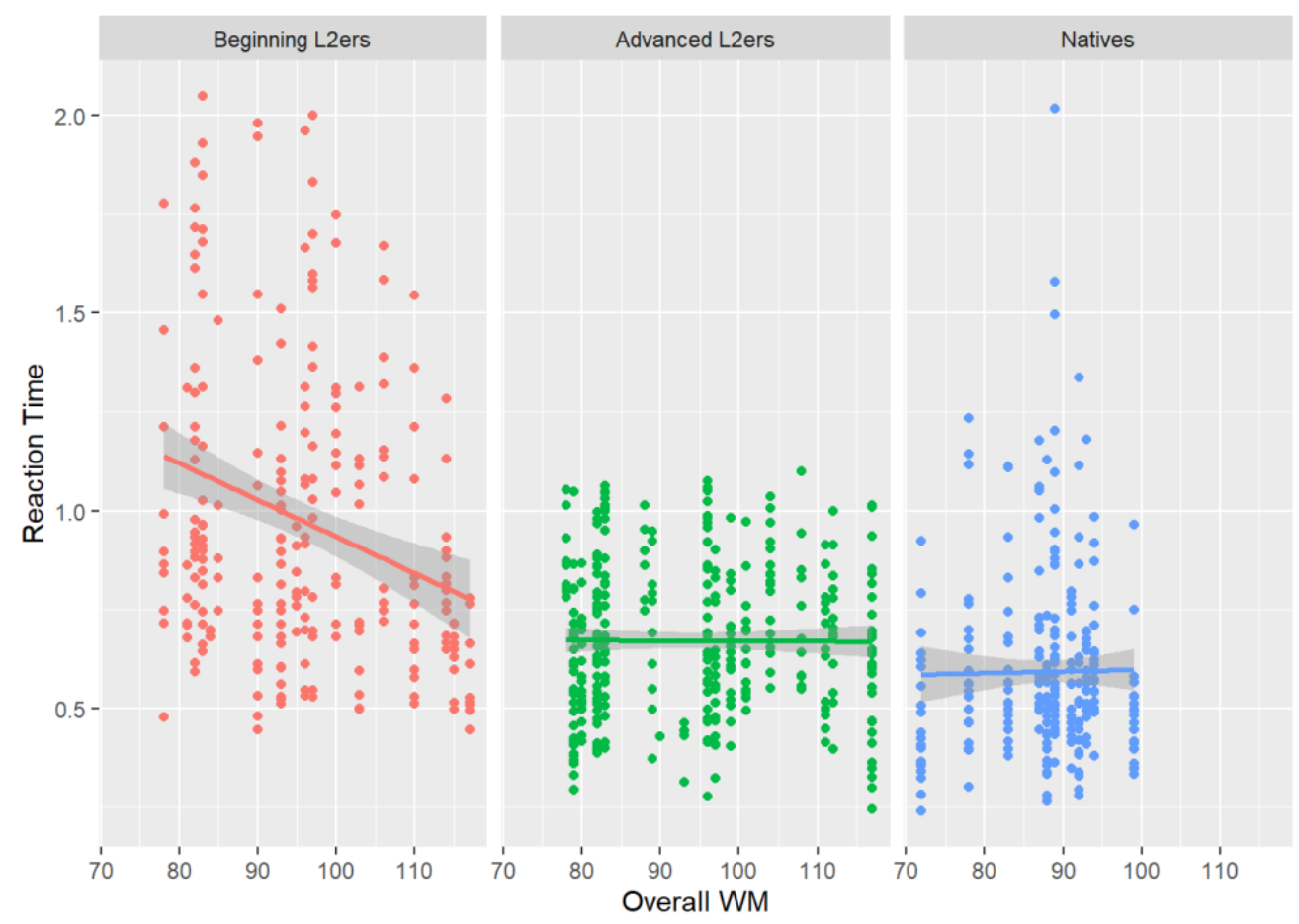

\section{Discussion}

This study investigated the effects of morphological complexity, individual surface frequency, L2 proficiency and WM on the processing of derived Spanish verbs by English L2 learners of Spanish and Spanish monolinguals. This question is important for several 
reasons: very little research has been conducted on word structure processing in Spanish, most studies have used corpus-based frequency to measure familiarity with words instead of individual exposure, and the role of WM in the selection of a specific processing route has not been assessed.

The first research question pertained to whether L2 learners of Spanish and Spanish monolinguals employed a decomposition or a whole unit processing route, and whether proficiency in the L2 and individual frequency modulated the processing of morphological information. The second research question was whether WM was responsible for the selection of a morphological processing strategy over the other. Results for each research question will be discussed in detail below.

\section{RQ 1: Effects of exposure and L2 proficiency on L2 processing of morphologically} complex Spanish words.

My predictions that beginners would break L2 words down into their morphemes and that advanced L2 learners and native Spanish speakers would employ both strategies depending on their exposure to a given word were partially supported. I assumed that longer RTs in words with greater number of morphemes would indicate that participants are analyzing morphological information in the word recognition process, and that no significantly different RTs between these conditions would mean that speakers might be processing words with their morphology complete.

Overall, participants responded to low frequency words significantly slower than to high frequency words, as expected. When including the morphological complexity factor in the second GLMM, results revealed that beginners took significantly more time to process derived verbs with three morphemes than those with two morphemes that were low 
frequent for them. On the other hand, regarding highly frequent words, beginners took a similar amount of time to process words with three than words with two morphemes. Their advanced L2 learner peers and native Spanish speakers, in turn, did not take more time to process words with more morphemes, regardless of how frequent these words were for them. These findings suggest that at the early stages of L2 acquisition, learners of Spanish employ two distinct routes while processing morphologically complex, derived verbs in the L2. While the two processing strategies are available, the winning one is determined by the individual frequency of a given word for each subject in specific. Upon hearing a derived verb in the L2 that is not very frequent for them, beginners break the word down into its different morphemes prior to lexical access, a process that takes more time the higher number of morphemes an L2 word has. On the other hand, L2 learners seem to make use of a whole word processing strategy for highly frequent words. In addition, the said findings suggest that it is possible for L2 learners to gain native-like morphological processing upon reaching high proficiency in the $\mathrm{L} 2$.

It could be argued that even though low proficient L2 learners have had enough exposure to low frequent words in order to develop a separate lexical entry for them, the low rate of occurrence of these words has not allowed them to automatize the recognition process for these words. The parsing strategy is more time costly and less efficient than whole word processing, as it can lead to parsing errors. Once the decomposition process for a specific word has been performed a sufficient number of times, the processor can opt for a processing strategy that accelerates word recognition, as it does not require the further application of morphological operations. This interpretation of the results is in partial agreement with the predictions of the AAM (Burani \& Laudanna, 1992; Caramazza, 
Laudanna \& Romani, 1988), which posits that native speakers deploy two different processing routes based on their surface frequency to overcome word recognition. The extension of a monolingual-based account to an L2 population is therefore partially successful, as only L2 learners showed empirical evidence of deploying both a decomposition and whole word route. However, a decomposition strategy cannot be discarded for Spanish monolinguals. The findings do not indicate that this group is unable to parse lexical items based on their apparent morphological components or that they never make use of this route. Spanish monolinguals may indeed use a decomposition route while comprehending novel words with transparent derivational affixes (e.g., desromper, unbreak in English) as some studies suggest (e.g., Lewis, Solomyak \& Marantz, 2011) or when producing words.

The findings replicate those studies in which monolinguals employ a whole word route only (Gürel \& Uygun, 2013; Portin \& Laine, 2001; Uygun \& Gürel, 2016), in which L2 learners with low proficiency showed a dual-route mechanism (Gürel \& Uygun, 2013; Portin, Lehtonen \& Laine, 2007; Uygun \& Gürel, 2016), and those in which advanced L2 learners processed morphologically complex words in a native-like manner (e.g., Gürel \& Uygun, 2013; Portin, Lehtonen \& Laine, 2007; Uygun \& Gürel, 2016). In addition, the findings partially agree with studies claiming that low proficient L2 learners employ a decomposition route (Coughlin \& Tremblay, 2015; Foote, 2017; Gor, Chrabaszcz \& Cook, 2018; Gor \& Jackson, 2013; Lehtonen \& Laine, 2003), and in which native speakers process some units as wholes (Gürel, 1999; Lehtonen et al., 2012). Moreover, the findings partially agree with the notion that L2 speakers share the same word structure processing mechanisms as L1 speakers of the target language (Diependaele., Duñabeitia, Morris \& 
Keuleers, 2011), although this notion only applies to L2 learners of advanced proficiency. In other words, the findings suggest that native-like morphological processing is attainable for L2 learners, and that learners switch their processing strategy to resemble that of native speakers of the target language as proficiency increases.

Also, auditory morphological processing, an understudied phenomenon, seems to be analogous to morphological processing in visual tasks, as findings from this study converge entirely with some of those found with visual tasks (e.g., Uygun \& Gürel, 2016). Furthermore, English beginning L2 learners of Spanish seem to make use of their L1 processing strategy (i.e., both decomposition and whole word processing; see Beyersmann, Coltheart \& Castles, 2012) while dealing with L2 morphological processing. In other words, English L1 processing strategies can likely transfer to the L2 during the early stages of L2 acquisition.

However, the findings of the present study do not support an L2 (Coughlin, Fiorentino, Royle \& Steinhauer, 2019; De Grauwe et al., 2014) or L1 (Brooks \& Cid de Garcia, 2015; Coughlin \& Tremblay, 2015; Coughlin et al., 2019; Gor et al., 2018; McCormick, Brysbaert \& Rastle, 2009) obligatory decomposition route. Furthermore, the findings do not support accounts suggesting that the processor makes no use of morphological manipulation in the early stages of L2 acquisition (Clahsen \& Felser, 2006, 2018; Clahsen, Felser, Neubauer, Sato and Silva, 2010; Clahsen \& Neubauer, 2010). Most of these studies did not control for many critical variables on word recognition, including number of syllables, neighborhood density, phonotactic probability, or differential morphological complexity across conditions. Moreover, some of the said studies did not select stimuli varying in word frequency. This methodological aspect may be the culprit of 
failing to find a dual route mechanism in L2 learners. Those studies that did include surface frequency measured it using corpora, thus not attending to a more realistic lexical frequency variable: the actual frequency that a given word has for each particular participant (i.e., individual surface frequency). Individual surface frequency is naturally more accurate in assessing frequency of occurrence of a given word in a particular participant. It is likely that variables such as profession, reading habits, vocabulary size, or communicative needs among participants make individual surface frequency significantly different from established corpus-based frequency for a given language.

It is important to note, however, that studies have explored word structure processing in different languages (e.g., Dutch, English, French, Russian, Turkish). To account for the different results among studies, and instead of claiming methodological deficiencies in the previous literature, it could be argued that morphological processing routes are language dependent. In other words, each language may select a preferred morphological processing route (e.g., Turkish and Spanish: whole word processing; French and English: full decomposition) based on its intrinsic morphological characteristics. However, it is still unclear what specific morphological rules of a given language make native speakers favor one processing strategy over the other. This language-specific route account contradicts a view where the selection of a word structure processing strategy is universal and therefore, language independent (Beyersmann et al., 2013), a dichotomy within word structure processing that should be thoroughly explored in future studies.

\section{$R Q$ 2: The role of $W M$ in $L 1$ and $L 2$ morphological processing}

The prediction that the selection of a particular morphological processing route is independent of WM capacity was supported. Results suggest that, while a higher WM 
capacity allowed beginner L2 learners to recognize L2 words faster, WM was not involved in the processing of morphological complexity in any of the groups. In other words, WM capacity did not determine which route native speakers or L2 learners deployed. This finding suggests that the dual route nature of word structure processing in the early stages of L2 Spanish and the whole word route in advanced learners and Spanish monolinguals is not the result of cognitive constraints, but rather a linguistically driven phenomenon, which, as was mentioned above, might be language specific. Another possible explanation is that L1 or L2 lexical processing does not require to put a great amount of linguistic information (i.e., morphology/semantics) on hold while processing incoming information (i.e., morphology/phonology), which might not require a high WM capacity to accomplish the task. It would make sense that sentence processing requires the use of WM capacity while morphological processing does not, as the former process requires that pragmatic, semantic, morphological information for a greater number of segments is put on hold while processing not only words, but also complex hierarchical relations across them, such as agreement, anaphora, or thematic roles.

The results of the present study provide valuable contributions to the field in spite of their limitations. The first limitation is that WM was measured only through one task. Future studies should include several tasks that tap into the different subcomponents of this cognitive ability and assess global WM capacity through a composite of the different scores obtained. This procedure would provide a more comprehensive measurement of WM. Second, experimental stimuli in the present study varied in one morpheme (two- and threemorpheme words). Stimuli could not vary in more than one morpheme, as they were matched for numerous variables affecting RTs, including syllable length. The lack of 
decomposition effects for Spanish monolinguals was due plausibly to insufficient morphological complexity variation across stimuli. Therefore, studies should investigate languages in which multiple morphemes can occur in a same syllable. In addition, given that the present study is one of the first ones in exploring word structure processing in Spanish in general, and especially auditorily, it is recommended that future studies explore this phenomenon through visual word recognition tasks. A final suggestion for future studies is to explore whether each language has a specific default morphological processing route by comparing different languages using the same methodology. If this is proven the case, then language-specific theories of lexical access and word recognition should be put forward to account for cross linguistic differences in word structure processing.

\section{Conclusion}

The purpose of the present study was to evaluate the role of morphological complexity, L2 proficiency, individual surface frequency and WM in how English L2 learners of Spanish and Spanish monolinguals process derived verbs auditorily. Results revealed that beginning English L2 learners of Spanish decomposed derived verbs when these were low frequent for them, and they processed highly frequent words as wholes. Advanced L2 learners and Spanish native speakers, on the other hand, constantly used a whole word route, thus being unaffected by individual surface frequency. These findings support the AAM model (Burani \& Laudanna, 1992; Caramazza et. al, 1988) in the early stages of L2 acquisition, but not in Spanish monolingual populations. Also, the findings provide evidence that it is possible for L2 learners to achieve native-like word structure processing, and that L2 learners switch their processing strategies as a function of their proficiency in the L2. Regarding WM effects, WM capacity did not modulate the selection 
of a decomposition or whole word processing strategy. However, higher WM beginners were faster at recognizing L2 words than their low WM peers. This finding suggests that the employment of a specific processing strategy is due to linguistic reasons, rather than cognitive constraints. Taken together, these findings suggest that there are qualitative differences between L1 and L2 processing only for the initial stages of L2 acquisition, and that L2 speakers are able to recognize morphological structures in the L2 regardless of the capacity of their cognitive abilities.

\section{Appendix}

Stimuli set for the auditory lexical decision task, listed in alphabetical order.

2 morphemes (stem-inflectional affix) 3 morphemes (derivational affix-stem-inflectional affix)

\begin{tabular}{cc}
\hline abarc-ar 'to cover' & a-bland-ar 'to soften' \\
abrig-ar 'wrap up warm' & a-bon-ar 'to pay' \\
abund-ar 'to be plentiful' & a-braz-ar 'to hug' \\
aceit-ar 'to oil' & a-brevi-ar 'to shorten' \\
acost-ar 'to lay down' & a-cerc-ar 'to put something closer' \\
acus-ar 'to charge' & a-cert-ar 'to hit the target' \\
adapt-ar 'to adjust' & a-chic-ar 'to shrink' \\
afeit-ar 'to shave' & a-clam-ar 'to laud' \\
agobi-ar 'to overwhelm' & a-cort-ar 'to abridge' \\
agreg-ar 'to add' & a-fil-ar 'to sharpen' \\
ahog-ar 'to drown' & a-fin-ar 'to refine' \\
alab-ar 'to praise' & a-floj-ar 'to loosen' \\
alegr-ar 'to cheer up' & a-garr-ar 'to grab' \\
alert-ar 'to warn' & a-grup-ar 'to group' \\
amarg-ar 'to embitter' & a-larg-ar 'to lengthen' \\
anim-ar 'to encourage' & a-mas-ar 'to knead' \\
apel-ar 'to appeal' & a-not-ar 'to write down' \\
apost-ar 'to bet' & a-plaz-ar 'to postpone' \\
arañ-ar 'to scratch' & a-prob-ar 'to pass' \\
arrest-ar 'to detain' & a-rriesg-ar 'to risk'
\end{tabular}




$$
\begin{aligned}
& \text { arrib-ar 'to arrive' } \\
& \text { arroj-ar 'to throw' } \\
& \text { asoci-ar 'to link' } \\
& \text { asom-ar 'to lean out' }
\end{aligned}
$$

$$
\begin{aligned}
& \text { a-rruin-ar 'to ruin' } \\
& \text { a-sust-ar 'to frighten' } \\
& \text { a-tenu-ar 'to mitigate' } \\
& \text { a-viv-ar 'to intensify' }
\end{aligned}
$$

\section{References}

Aguasvivas, J., Carreiras, M., Brysbaert, M., Mandera, P., Keuleers, E., \& Duñabeitia, J. A. (2020). How do Spanish speakers read words? Insights from a crowdsourced lexical decision megastudy. Behavior Research Methods, 1-16.

Auer, E. T., \& Luce, P. A. (2005). Probabilistic phonotactics in spoken word recognition.

In D. B. Pisoni \& R. E. Remez (Eds.), The handbook of speech perception (pp. 610630). Oxford, UK: Blackwell.

Baayen, R. H., Dijkstra, T., \& Schreuder, R. (1997). Singulars and plurals in Dutch:

Evidence for a parallel dual-route model. Journal of Memory and Language, 37(1), 94-117.

Baayen, R. H., Wurm, L., \& Aycock, J. (2007). Lexical dynamics for low-frequency complex words: A regression study across tasks and modalities. The Mental Lexicon, 3, 419-486.

Baddeley, A. (2000). The episodic buffer: A new component of working memory? Trends in Cognitive Sciences, 4, 417-423

Baddeley, A. D., \& Hitch, G. J. (1974). Working memory. In G. H. Bower (Ed.), The psychology of learning and motivation: Advances in research and theory (Vol. 8, pp. 47-89). New York, NY: Academic Press.

Bates, D., \& Maechler, M. (2009). lme4: Linear Mixed-Effects Models Using S4 Classes. R package version 0.999375-32. http://CRAN.R-project.org/package=lme4. 
Beyersmann, E., Coltheart, M., \& Castles, A. (2012). Parallel processing of whole words and morphemes in visual word recognition. The Quarterly Journal of Experimental Psychology, 65(9), 1798-1819.

Beyersmann, E., Duñabeitia, J. A., Carreiras, M., Coltheart, M., \& Castles, A. (2013). Early morphological decomposition of suffixed words: Masked priming evidence with transposed-letter nonword primes. Applied psycholinguistics, 34(5), 869-892.

Brooks, T. L., \& Cid de Garcia, D. (2015). Evidence for morphological composition in compound words using MEG. Frontiers in human neuroscience, 9, 215.

Burani, C., \& Caramazza, A. (1987). Representation and processing of derived words. Language and cognitive processes, 2(3-4), 217-227.

Burani, C., \& Laudanna, A. (1992). Units of representation for derived words in the lexicon. In R. Frost \& L. Katz (Eds.), Orthography, phonology, morphology and meaning. Amsterdam: North-Holland.

Burani, C., Salmaso, D., \& Caramazza, A. (1984). Morphological structure and lexical access. Visible Language, 18(4), 342-352.

Butterworth, B. (1983). Lexical representation. In B. Butterworth (Ed.), Language production (pp. 257-294). London, England: Academic Press.

Caramazza, A., Laudanna, A., \& Romani, C. (1988). Lexical access and inflectional morphology. Cognition, 28(3), 297-332.

Chen, S., Miao, X., \& Fang, J. (2007). An experimental study on the storage units of English words in English-Chinese bilingual mental lexicon. Foreign Language Teaching and Research, 40(1), 51-55. 
Chetail, F. (2014). Effect of number of syllables in visual word recognition: new insights from the lexical decision task. Language, Cognition and Neuroscience, 29(10), $1249-1256$.

Clahsen, H. \& Felser, C. (2006). Grammatical processing in language learners. Applied Psycholinguistics, 27(1), 3-42.

Clahsen, H., \& Felser, C. (2018). Some notes on the shallow structure hypothesis. Studies in Second Language Acquisition, 40(3), 693-706.

Clahsen, H., Felser, C., Neubauer, K., Sato, M. \& Silva, R. (2010). Morphological structure in native and non-native language processing. Language Learning, 60, 21-48.

Clahsen, H., \& Neubauer, K. (2010). Morphology, frequency, and the processing of derived words in native and non-native speakers. Lingua, 120(11), 2627-2637.

Cockcroft, K., Wigdorowitz, M., \& Liversage, L. (2019). A multilingual advantage in the components of working memory. Bilingualism: Language and Cognition, 22(1), 1529.

Conway, A. R. A., Jarrold, C., Kane, M. J., Miyake, A., \& Towse, J. N. (Eds.). (2007). Variation in working memory. Oxford: New York, NY.

Coughlin, C. E., Fiorentino, R., Royle, P., \& Steinhauer, K. (2019). Sensitivity to inflectional morphology in a non-native language: evidence from ERPs. Frontiers in Communication, 4, 21.

Coughlin, C. E., \& Tremblay, A. (2013). Proficiency and working memory based explanations for nonnative speakers' sensitivity to agreement in sentence processing. Applied Psycholinguistics, 34(3), 615-646. 
Coughlin, C. E., \& Tremblay, A. (2015). Morphological decomposition in native and nonnative French speakers. Bilingualism: Language and cognition, 18(3), 524-542.

De Grauwe, S., Lemhöfer, K., Willems, R. M., \& Schriefers, H. (2014). L2 speakers decompose morphologically complex verbs: fMRI evidence from priming of transparent derived verbs. Frontiers in human neuroscience, 8, 1-12.

Duñabeitia, J. A., Perea, M., \& Carreiras, M. (2007). Do transposed-letter similarity effects occur at a morpheme level? Evidence for morpho-orthographic decomposition. Cognition, 105(3), 691-703.

Diependaele, K., Duñabeitia, J. A., Morris, J., \& Keuleers, E. (2011). Fast morphological effects in first and second language word recognition. Journal of Memory and Language, 64(4), 344-358.

Domínguez, A., de Vega, M., \& Barber, H. (2004). Event-related brain potentials elicited by morphological, homographic, orthographic and semantic priming. Journal of cognitive neuroscience, 16(4), 598-608.

Dronjic, V. (2013). Concurrent memory load, working memory span, and morphological processing in L1 and L2 English (Doctoral dissertation).

Durand López, E.M. (In press). A bilingual advantage in memory capacity: Assessing the roles of proficiency, number of languages acquired and age of acquisition. International Journal of Bilingualism.

Ellis, N. C. (2002). Frequency effects in language processing: A review with implications for theories of implicit and explicit language acquisition. Studies in Second Language Acquisition, 24, 143-188. 
Estivalet, G.L., \& Meunier, F. (2019). Bilingual processing on French verbs: Lexicon organization and morphological structures. Journal of Humanities and Social Science, 6(5), 46-57.

Foote, R. (2017). The storage and processing of morphologically complex words in L2 Spanish. Studies in second language acquisition, 39(4), 735-767.

Gathercole, S. E., \& Baddeley, A. D. (2014). Working memory and language. Psychology Press.

Hur, E. (2021). Does lexical frequency matter? The acquisition of the differential object marking among L2 learners and Heritage Speakers. Ph.D. dissertation, Rutgers University.

Gollan, T., Montoya, R., Fennema-Notestine, C., \& Morris, S. (2005). Bilingualism affects picture naming but not picture classification. Memory \& Cognition, 33(7), 12201234.

Gor, K., Chrabaszcz, A., \& Cook, S. (2018). Early and late learners decompose inflected nouns, but can they tell which ones are inflected correctly?. Journal of Second Language Studies, 1(1), 106-140.

Gor, K., \& Jackson, S. (2013). Morphological decomposition and lexical access in a native and second language: A nesting doll effect. Language and cognitive processes, 28(7), 1065-1091.

Grosjean, F. (1998). Studying bilinguals: Methodological and conceptual issues. Bilingualism: Language and cognition, 1(2), 131-149. 
Guasch, M., Boada, R., Ferré, P., \& Sánchez-Casas, R. (2013). NIM: A Web-based Swiss Army knife to select stimuli for psycholinguistic studies. Behavior Research Methods, 45, 765-771.

Gürel, A. (1999). Decomposition: To what extent? The case of Turkish. Brain and Language, 68, 218-224.

Gürel, A., \& Uygun, S. (2013). Representation of multimorphemic words in the mental lexicon: Implications for second language acquisition of morphology. Proceedings of the 37th Annual Conference on Language Development, 122-133.

Havik, E., Roberts, L., Van Hout, R., Schreuder, R., \& Haverkort, M. (2009). Processing subject-object ambiguities in the L2: A self-paced reading study with German L2 learners of Dutch. Language Learning, 59, 73-112.

Hur, E., López Otero, J. C., \& Sánchez, L. (2020). Gender Agreement and Assignment in Spanish Heritage Speakers: Does Frequency Matter?. Languages, 5(4), 48, 1-16.

Juffs, A., \& Harrington, M. (2011). Aspects of working memory in L2 learning. Language teaching, 44(2), 137-166.

Kuperman, V., Bertram, R., \& Baayen, R. H. (2008). Morphological dynamics in compound processing. Language and Cognitive Processes, 23, 1089-1132.

Laudanna, A., Badecker, W., \& Caramazza, A. (1989). Priming homographic stems. Journal of Memory and Language, 28(5), 531-546.

Laudanna, A., Badecker, W., \& Caramazza, A. (1992). Processing inflectional and derivational morphology. Journal of Memory and Language, 31(3), 333-348.

Lázaro, M. (2012). The effects of base frequency and affix productivity in Spanish. The Spanish Journal of Psychology, 15(2), 505-512. 
Lehtonen, M., Hultén, A., Rodríguez-Fornells, A., Cunillera, T., Tuomainen, J., \& Laine, M. (2012). Differences in word recognition between early bilinguals and monolinguals: Behavioral and ERP evidence. Neuropsychologia, 50(7), 1362-1371.

Lehtonen, M., \& Laine, M. (2003). How word frequency affects morphological processing in monolinguals and bilinguals. Bilingualism: Language and cognition, 6(3), 213225.

Lehtonen, M., Niska, H., Wande, E., Niemi, J., \& Laine, M. (2006). Recognition of inflected words in a morphologically limited language: Frequency effects in monolinguals and bilinguals. Journal of Psycholinguistic Research, 35(2), 121.

Lewis, G., Solomyak, O., \& Marantz, A. (2011). The neural basis of obligatory decomposition of suffixed words. Brain and language, 118(3), 118-127.

Liang, L., \& Chen, B. (2014). Processing morphologically complex words in secondlanguage learners: The effect of proficiency. Acta Psychologica, 150, 69-79.

Lignos, C., \& Gorman, K. (2012). Revisiting frequency and storage in morphological processing. In Proceedings from the Annual Meeting of the Chicago Linguistic Society (Vol. 48, No. 1, pp. 447-461). Chicago Linguistic Society.

Longtin, C. M., \& Meunier, F. (2005). Morphological decomposition in early visual word processing. Journal of Memory and Language, 53(1), 26-41.

López Otero, J. C. (2020). The acquisition of the syntactic and morphological properties of Spanish imperatives in heritage and second language speakers. Ph.D. dissertation, Rutgers University. 
Marian, V., Blumenfeld, H. K., \& Kaushanskaya, M. (2007). The Language Experience and Proficiency Questionnaire (LEAP-Q): Assessing language profiles in bilinguals and multilinguals. Journal of Speech, Language, and Hearing Research.

McCormick, S. F., Brysbaert, M., \& Rastle, K. (2009). Is morphological decomposition limited to low-frequency words?. The Quarterly Journal of Experimental Psychology, 62(9), 1706-1715.

McDonald, J. L. (2006). Beyond the critical period: Processing-based explanations for poor grammaticality judgment performance by late second language learners. Journal of Memory and Language, 55, 381-401.

Meunier, F., \& Longtin, C. M. (2007). Morphological decomposition and semantic integration in word processing. Journal of Memory and Language, 56(4), 457-471.

Osaka, M., \& Osaka, N. (1992). Language-independent working memory as measured by Japanese and English reading span tests. Bulletin of the Psychonomic Society, 30(4), 287-289.

Portin, M., \& Laine, M. (2001). Processing cost associated with inflectional morphology in bilingual speakers. Bilingualism: Language and Cognition, 4(1), 55-62.

Portin, M., Lehtonen, M., \& Laine, M. (2007). Processing of inflected nouns in late bilinguals. Applied Psycholinguistics, 28(1), 135.

R Core Team (2020) R: A language and environment for statistical computing. R Foundation for Statistical Computing, Vienna, Austria. Retrieved from https://www.R-project.org/ 
Rastle, K., Davis, M. H., Marslen-Wilson, W. D., \& Tyler, L. K. (2000). Morphological and semantic effects in visual word recognition: A time-course study. Language and cognitive processes, 15(4-5), 507-537.

Rodríguez, G. A. (2008). Second language sentence processing: Is it fundamentally different? [Doctoral dissertation]. University of Pittsburgh, Pittsburgh.

Sagarra, N. (2007). Online processing of gender agreement in low proficient EnglishSpanish late bilinguals. In M. J. Cabrera, J. Camacho, V. Déprez, N. Flores, \& L. Sánchez (Eds.), Romance linguistics 2006: Selected papers from the 36th Linguistic Symposium on Romance Languages (pp. 240-253). Amsterdam: John Benjamins

Sagarra, N. \& Herschensohn, J. (2010). The role of proficiency and working memory in gender and number agreement processing in L1 and L2 Spanish. Lingua, 20, 20222039.

Santiago, F., Singh, P., \& Sri, L. (2017). Building Cognitive Applications with IBM Watson Services: Volume 6 Speech to Text and Text to Speech. IBM Redbooks.

Schreuder, R., \& Baayen, R. H. (1995). Modeling morphological processing. In L. B. Feldman (Ed.), Morphological aspects of language processing (pp. 131-154). Hillsdale, NJ: Erlbaum.

Sebastián-Gallés, N., Cuetos, F., Carreiras, M., \& Martí-Antonin, M. (2000). LEXESP. Léxico informatizado del español. Barcelona: Publicacions de la Universitat de Barcelona.

Shahnazari-Dorcheh, M., \& Roshan, S. (2012). Developing a Non-Language Related Span Test for the Use in Language-Specific and Cross-Language Studies. English Language Teaching, 5(11), 104-110. 
Slabakova, R., Kempchinsky, P., \& Rothman, J. (2012). Clitic-doubled left dislocation and focus fronting in L2 Spanish: A case of successful acquisition at the syntaxdiscourse interface. Second Language Research, 28(3), 319-348.

Serrano-Dolader, D. (2017). La parasíntesis como proceso lexicogenético (no tan) peculiar. In J. Pena (Ed.), Procesos morfológicos. Zonas de interferencia (pp. 49-76). Universidade de Santiago de Compostela.

Soveri, A., Lehtonen, M., \& Laine, M. J. (2007). Word frequency and morphological processing in Finnish revisited. The mental lexicon, 2(3), 359-385.

Stockall, L., \& Marantz, A. (2006). A single route, full decomposition model of morphological complexity: MEG evidence. The mental lexicon, 1(1), 85-123.

Taft, M. (1979). Recognition of affixed words and the word-frequency effect. Memory \& Cognition, 7, 263-272.

Taft, M. (1994). Interactive activation as a framework for understanding morphological processing. Language \& Cognitive Processes, 9, 271-294.

Taft, M. (2004). Morphological decomposition and the reverse base frequency effect. The Quarterly Journal of Experimental Psychology Section A, 57(4), 745-765.

Taft, M., \& Ardasinski, S. (2006). Obligatory decomposition in reading prefixed words. The Mental Lexicon, 1(2), 183-199.

Taft, M., \& Forster, K. I. (1975). Lexical storage and retrieval of prefixed words. Journal of verbal learning and verbal behavior, 14(6), 638-647.

Ullman, M. T. (2005). A cognitive neuroscience perspective on second language acquisition: The declarative/procedural model. In C. Sanz (ed.), Mind and context in 
adult second language acquisition: Methods, theory, and practice (pp. 141-178). Washington, DC: Georgetown University Press.

Uygun, S., \& Gürel, A. (2016). Processing morphology in L2 Turkish. Second language acquisition of Turkish, 59, 251-279.

Vannest, J., Bertram, R., Järvikivi, J., \& Niemi, J. (2002). Counterintuitive cross-linguistic differences: More morphological computation in English than in Finnish. Journal of Psycholinguistic Research, 31(2), 83-106.

Vitevitch, M.S., \& Luce, P.A. (2004) A web-based interface to calculate phonotactic probability for words and nonwords in English. Behavior Research Methods, Instruments, and Computers, 36, 481-487.

Vitevitch, M. S., \& Luce, P. A. (2005). Increases in phonotactic probability facilitate spoken nonword repetition. Journal of Memory and Language, 52, 193-204.

Vitevitch, M.S., \& Luce, P. (2016). Phonological neighborhood effects in spoken word perception and production. Annual Review of Linguistics, 2, 75-94.

Wen, Z., Mota, M. B., \& McNeill, A. (Eds.). (2015). Working memory in second language acquisition and processing (Vol. 87). Multilingual Matters.

Xue, G., Dong, Q., Jin, Z., Chen, C. (2004). Mapping of verbal working memory in nonfluent Chinese-English bilinguals with functional MRI. Neuroimage, 22, 1-10. 